\title{
A systematic review of factors affecting adherence to malaria chemoprophylaxis amongst travellers from non-endemic countries
}

\author{
Julian Ahluwalia', Samantha K. Brooks² ${ }^{10}$, John Weinman ${ }^{3}$ and G. James Rubin²*
}

\begin{abstract}
Background: The aim of this systematic review was to identify predictors of actual or intended adherence with malaria chemoprophylaxis amongst travellers from non-endemic countries visiting endemic countries.

Methods: A systematic review of the literature was conducted using MEDLINE, Embase, PsycINFO and Global Health databases for studies published up to April 2019. Studies were included if they assessed reasons for adherence among people travelling from a country where malaria was not endemic to a country where it was.

Results: Thirty-two studies were included. Predictors of adherence were categorized as relating to either the nature of the travel or the traveller themselves. The three main predictors associated with nature of travel included: destination (e.g. country visited, urban vs rural areas), length of travel and type of travel (e.g. package vs backpacking holiday). The four main traveller-associated predictors were: age, reason for travel (e.g. business, leisure or visiting friends and relatives), perceived risk of catching malaria and experienced or expected medication effects.

Conclusions: In order to improve adherence, clinicians should focus on travellers who are least likely to exhibit adherent behaviour. This includes travellers visiting destinations known to have lower adherence figures (such as rural areas), backpackers, business travellers, younger travellers and those travelling for longer periods of time. They should also check to ensure travellers' perceptions of the risks of malaria are realistic. Where appropriate, misperceptions (such as believing that curing malaria is easier than taking prophylaxis or that travellers visiting relatives have some level of innate immunity) should be corrected. All travellers should be informed of the potential side-effects of medication and given guidance on why it is nonetheless beneficial to continue to take prophylaxis. Further research is required to test interventions to improve adherence.
\end{abstract}

Keywords: Adherence, Uptake, Chemoprophylaxis, Prevention

\section{Background}

Malaria is a disease transmitted by female mosquitos of the genus Anopheles, which bite mainly in the evening and at night, and act as the primary vector for spreading the Plasmodium protozoa. Of the five parasite species that can cause malaria in humans, the most severe

*Correspondence: gideon.rubin@kcl.ac.uk

2 Department of Psychological Medicine, King's College London, Weston Education Centre, Cutcombe Road, London SE5 9RJ, UK

Full list of author information is available at the end of the article and deadly form of the disease is caused by Plasmodium falciparum. It is estimated that across the globe 3.2 billion people are at risk of malaria, making it one of the world's greatest public health concerns. The World Health Organization (WHO) [1] reported that in 2015 there were over 214 million cases of malaria and 438,000 deaths attributable to the disease. The demographics most at risk of malarial infection include pregnant women, young children and those visiting endemic countries from areas where malaria is not present [1]. 
Malaria is a notifiable disease in the UK, which has one of the highest rates of imported malaria in Europe [2].

Each year over 125 million international travellers are placed at risk of malaria infection by visiting the 97 countries and territories in the world where malaria is currently endemic [3]. Despite global mortality rates attributable to malaria falling by $60 \%$ since 2000 [1], it appears likely to become even more of a burden for some countries, such as Britain, due to both increased travel abroad and immigration from countries where malaria is prevalent. It is estimated that $10,000-30,000$ international travellers are affected by contracted malaria every year [4] with possible underreporting meaning that this figure could be higher. Of these cases, $90 \%$ of travellers do not develop symptoms until they return home [2].

Those travelling from non-endemic countries are placed at a significantly higher risk of malaria infection and consequences as they typically lack any immunity to malaria. In 2018, there were 1683 imported cases of malaria reported in the UK [5]. Delays in diagnosis, treatment and an increased risk of morbidity are possible for travellers arriving home to countries where clinicians are unfamiliar with malaria [6].

In order to avoid contracting malaria an individual may try to avoid bites (through mosquito nets, for example, or sprays) and using chemoprophylaxis. The use of anti-malarial medication to help prevent travellers from contracting malaria is strongly recommended by guidelines from the National Institute of Health and Clinical Excellence [7], with those visiting at-risk regions advised to take one of several types of tablet 1 to 3 weeks prior to, during, and 2 to 4 weeks after their trip [2]. Despite this, adherence to the full course of malaria prophylaxis medication is often sub-optimal, as shown in this review. Improving adherence may be the key to reducing rates of malaria among travellers and is emphasised in prevention guidance documents [8].

A growing body of research has explored the reasons why people often fail to adhere to medication across a range of contexts. One recent model of adherence specifies the importance of three broad categories of variable, suggesting that capability, motivation and opportunity predict behaviour [9]. Michie, van Stralen and West [10] define someone's capability as their 'psychological and physical capacity' to take part in a given activity; motivation relates to both automatic, habitual processes along with reflective reasoning; and opportunity encompasses all factors outside the individual including both social opportunity afforded by the cultural milieu and physical opportunity. Not all factors relating to adherence fall neatly within this model however, with some (such as forgetting) seeming to straddle categories.
This systematic review sought to identify the range of variables that have been identified as affecting adherence to currently used anti-malarial drugs given as prophylaxis to non-immune adults and children who are travelling to regions with endemic malaria.

\section{Methods}

The review was conducted in accordance with the preferred reporting items for systematic reviews and metaanalyses (PRISMA) guidelines [11].

\section{Search strategy}

A search was performed using Ovid, in the MEDLINE, Embase, PsycINFO and Global Health databases. Databases were searched from inception. The search was initially conducted on 28th December 2015, updated on 28th January 2017 and further updated on 4th April 2019. The following search terms were used: (malaria) AND (adherence OR compliance OR uptake) AND (prophyl* OR prevention OR atovaquone OR proguanil OR malarone OR chloroquine OR doxycycline OR mefloquine OR lariam OR primaquine). The results of this search were then filtered to remove duplicates and non-English results. Any studies categorized on the databases as 'non-human' were also removed. Those publications that were left were assessed for their relevance against the inclusion criteria by first screening their titles and abstracts and then screening the fulltexts of any that appeared potentially relevant.

\section{Inclusion criteria}

Studies were included if they:

- Presented original data (excluding, for example, review or commentary papers);

- Assessed people travelling from a non-endemic country to an endemic country;

- Assessed a non-military sample;

- Assessed the association between one or more variables and actual or intended adherence with malaria prophylaxis medication, or else described the self-reported reasons given by participants for their actual or intended adherence to malaria prophylaxis;

- Used a quantitative method (excluding purely qualitative studies);

- Were published in English;

- Were published as a full peer-reviewed paper (excluding, for example, conference papers and abstracts). 


\section{Data extraction}

For every included paper, details were tabulated relating to citation, year of publication, the sample that was studied, sample size, study design, the adherence rate to chemoprophylaxis, predictors of actual or intended adherence, self-reported reasons for actual or intended adherence, and a quality assessment grade. Any other details felt to be of importance in understanding the study were also noted.

Where possible, adherence rates for each study were calculated as the percentage of all participants who took all their tablets as recommended. It was not always possible to calculate this, however. For example, the nearest data reported by Cunningham et al. [12] was the percentage of participants who took more than $95 \%$ of their tablets as recommended.

\section{Quality assessment}

A methodological quality assessment was conducted based on a simplified version of the Delphi list [13]. Studies received one point for meeting each of the following criteria:

1. Eligibility criteria specified (with reasons for exclusion).

2. Large sample (i.e. over 1000 participants).

3. Appropriate statistical analysis and data reporting (such as $\mathrm{p}$ values) of significant predictors of adherence.

Studies scoring zero or one out of three were classified as 'low' quality. Those scoring two were classified as 'medium' quality. Studies scoring three were categorized as 'high' quality.

\section{Procedure}

The search, data extraction, assessment of risk of bias and data synthesis was carried out by JA with advice from GJR and JW. An updated search, data extraction, assessment of risk of bias and data synthesis was carried out by SKB with advice from GJR. Any uncertainties were resolved through discussion.

\section{Results}

The initial literature search resulted in a total of 2782 citations. After excluding duplicates, as well as nonhuman studies and studies not in English, 1592 citations were left. After screening of titles and abstracts, 51 papers appeared potentially relevant and were examined in full and 28 publications were included. One additional study was included following the 2017 update, bringing the total to 29 . Two additional studies were included following the 2019 update, thus increasing the total to 31.
One additional study [14] was identified during publication review, taking the total to 32 . Figure 1 shows the results of the initial search.

Included studies were conducted in several countries including the Netherlands, Germany, Canada, USA, UK, Israel and France, and with a wide range of participants including short and long-term travellers, those travelling for pleasure, those traveling for business, Peace Corps volunteers and others. Most studies relied on self-report questionnaires. Most used a cross-sectional design, asking returning travellers to report on their adherence.

Table 1 provides detailed information about the methods of each included study, together with adherence rates, factors associated with actual or intended adherence, and self-reported reasons for actual or intended adherence.

\section{Adherence rates}

Adherence rates varied widely, ranging from $0 \%$ for corporate workers placed in Ghana for over a year [27] to $89 \%$ for travellers from the USA [31].

\section{Self-reported reasons for non-adherence}

Forgetting to take the medication was reported as a reason for non-adherence in four studies [15, 33, 37, 40, 42]. Several studies also reported concerns with side-effects: this included concerns about the safety of long-term use of anti-malarial medication [12, 21, 40], as well as experienced (both past and present) or anticipated side-effects $[15,21,23,26-28,31,33,37,40,42]$. Other reasons included having too many pills to take [37]; not seeing any mosquitoes [28, 37, 42]; tiredness [37]; price [23, 37, 42]; lack of pills [37]; not thinking that prophylaxis was necessary [15, 21, 31]; being advised (for example, by a tour guide, locals or colleagues) that it was not necessary $[15,21,27,31,42]$ and not liking to take medication [33, 37]. A higher perceived risk of catching malaria was associated with greater adherence and having a self-reported low perceived risk [27, 42] was associated with poor adherence. Thinking there was no malaria [23] was associated with poor adherence, as was: presumed immunity $[23,26,33]$; high standard of on-site medical care, for example, at a mine in Mali [26]; taking an active decision not to take medication [22, 23]; being unable to obtain the tablets [23, 42]; thinking it is easier to cure malaria than to take the tablets [23,33]; having travelled for a short period and deciding to take the risk [23], losing the medication [42] and having travelled at short notice [15].

\section{Demographic risk factors}

Eleven studies found that older participants were more likely to be adherent $[12,17,18,20,21,24,30,32,38-40]$. Another study reported that those under 30 were less 
Studies identified through search $(\mathrm{n}=$ 2782)
Number excluded after excluding duplicates $(\mathrm{n}=868)$

Number excluded after screening for English language $(n=163)$

Number excluded after screening for human studies $(n=159)$
Titles and abstracts screened for eligibility $(n=1592)$
Studies excluded based on title and abstract $(\mathrm{n}=1541)$

\section{Full-text studies screened for} eligibility $(n=51)$
Number of studies included $(\mathrm{n}=28)$
Full-text studies excluded $(\mathrm{n}=23)$

Reasons for exclusion:

- No mention of reasons for, or against, adherence $(\mathrm{n}=$ 11)

- Military population $(\mathrm{n}=1)$

- Purely qualitative data on adherence $(\mathrm{n}=6)$

- Conference abstract $(\mathrm{n}=2)$

- Duplicate $(\mathrm{n}=3)$

Fig. 1 Search Tree (Search conducted on 28th December 2015. Results do not include one additional study identified in an update on 28th January 2017, two additional studies identified in an update on 4th April 2019 nor a study identified during publication review.)

likely to be adherent than older people [22], but significance was not reported. In addition, one study showed that those aged under 5 were significantly less likely to take their tablets correctly [36]. However, Joshi et al. [33] found that age was not a predictor of adherence as did Farquharson et al. [25].

A participant's country of residence was shown to influence adherence in three studies [18, 29, 41], though not in two studies [14, 42]. For example, Baggett et al. [29] showed that US citizens were significantly more likely to be adherent than non-US citizens; whilst Shady [41] found that those of Kuwaiti nationality are shown to have significantly better adherence when compared with non-Kuwaiti individuals.

Socio-economic and education status also influenced adherence rates. Blue-collar workers were more likely 


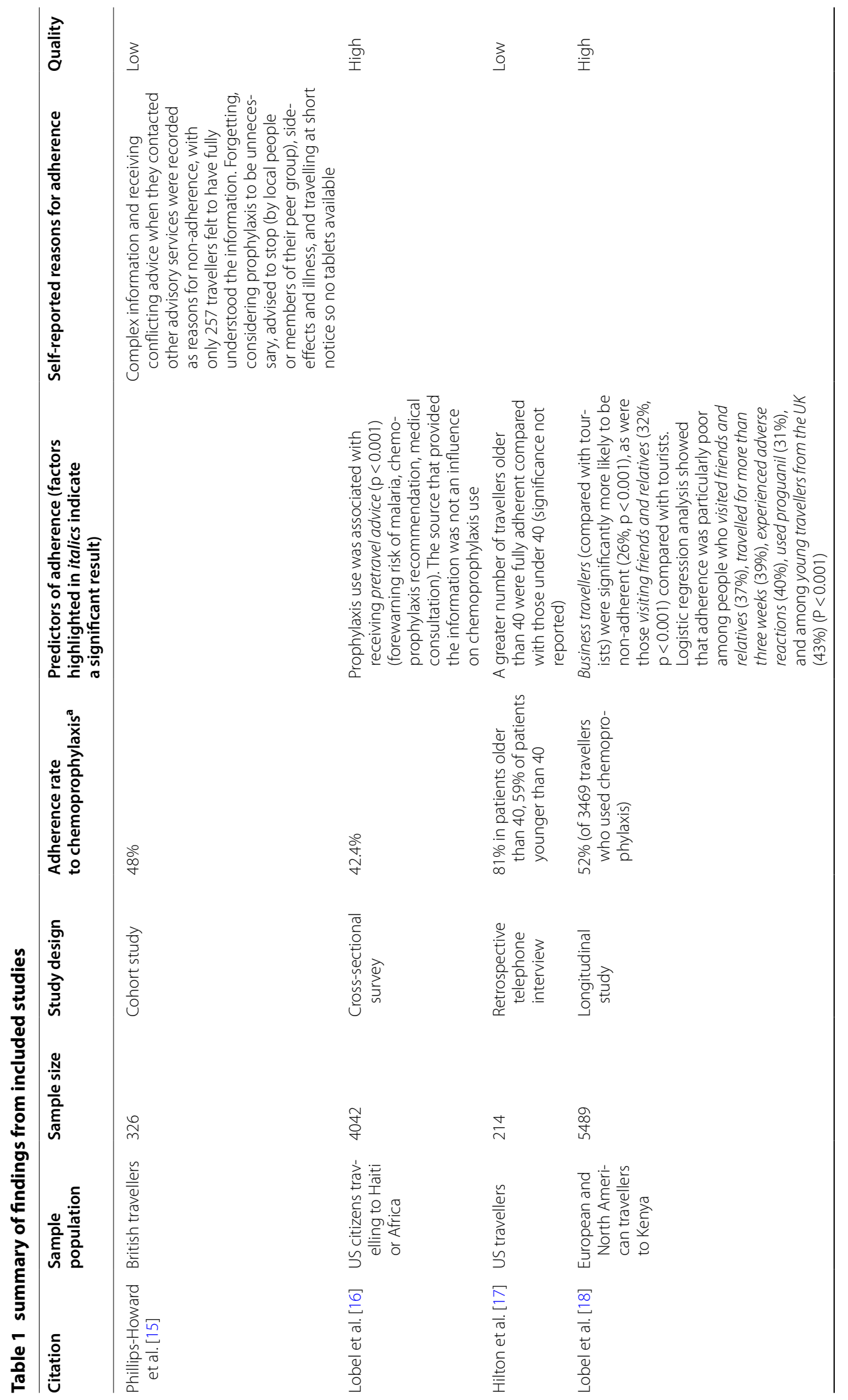




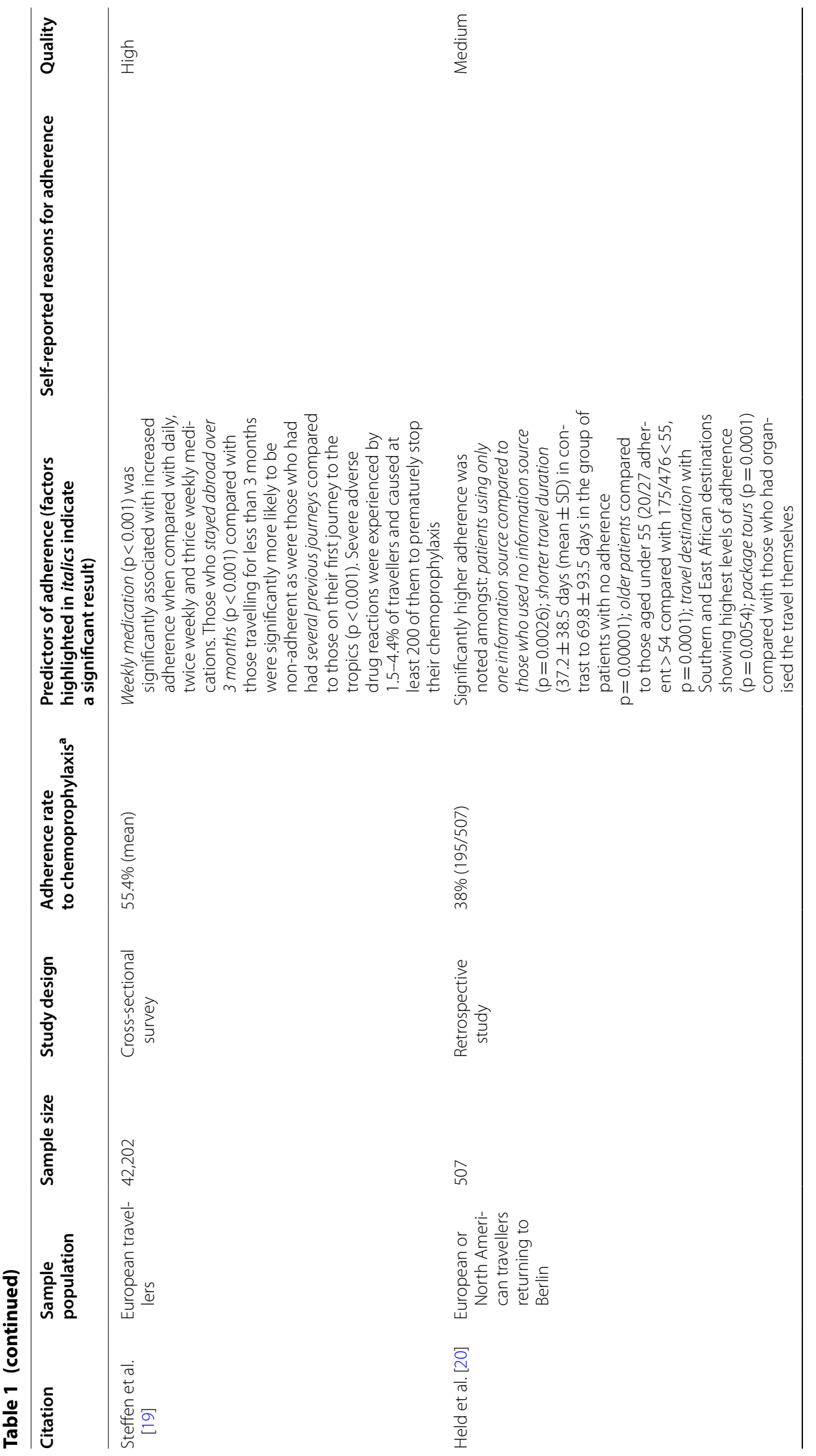




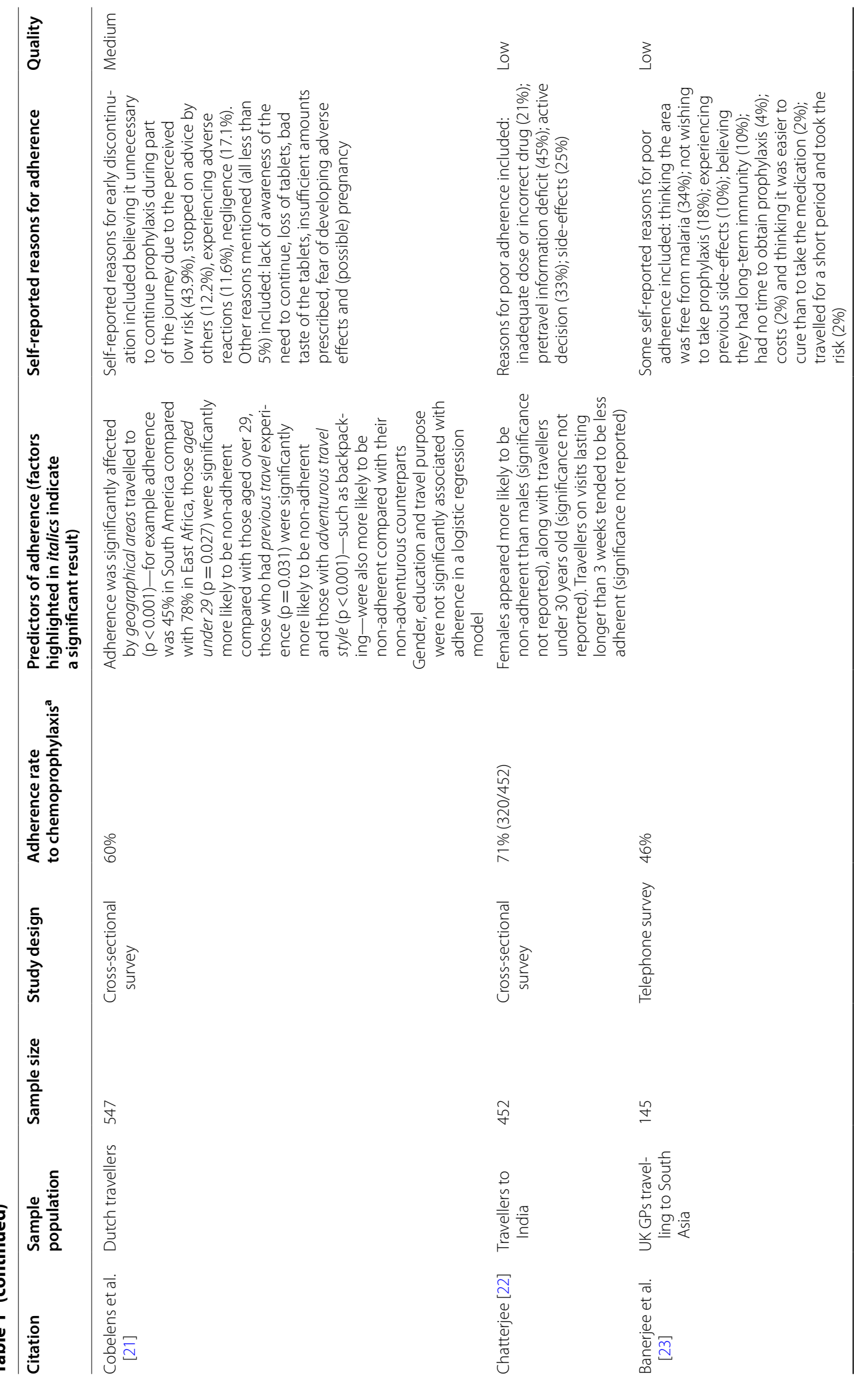




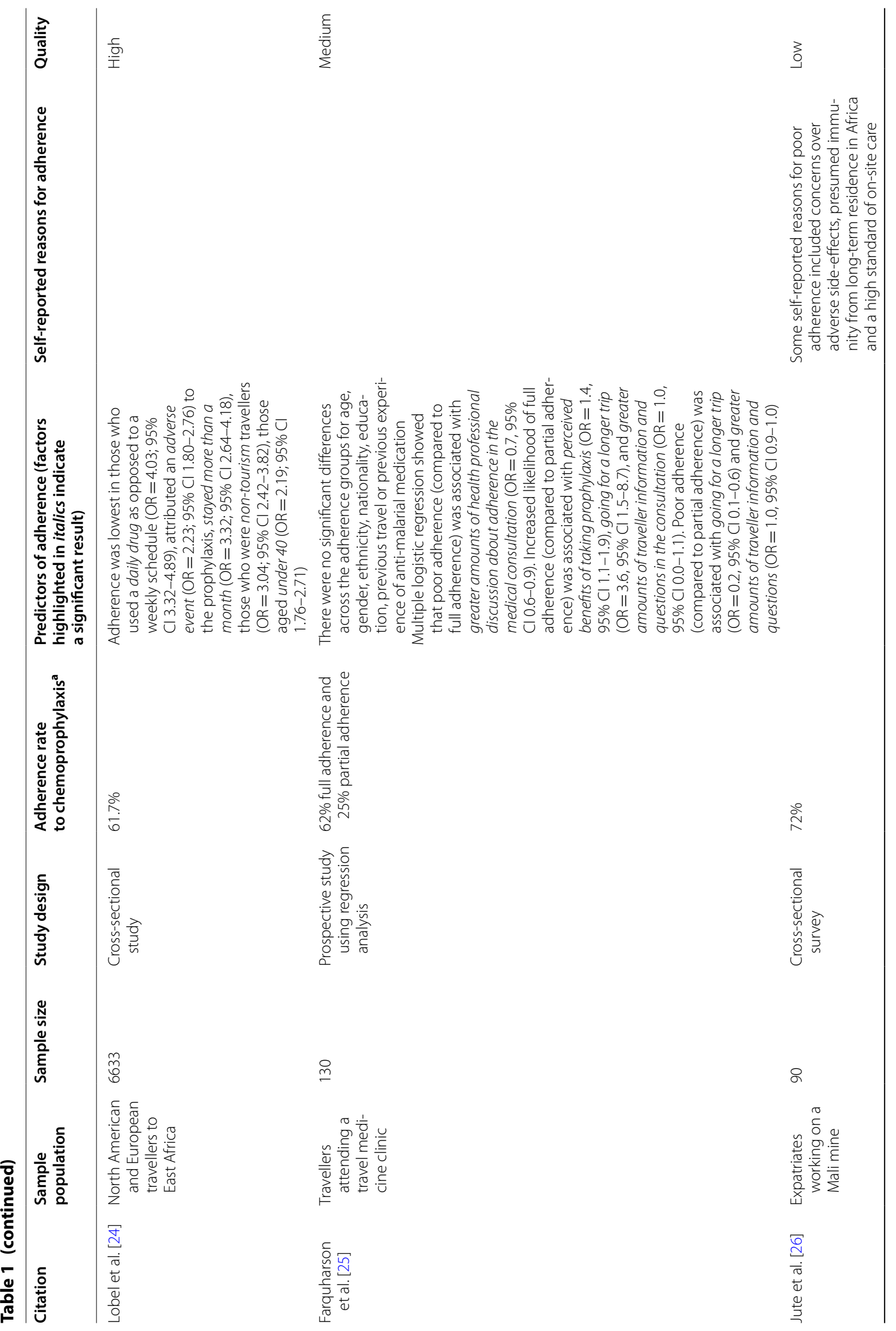




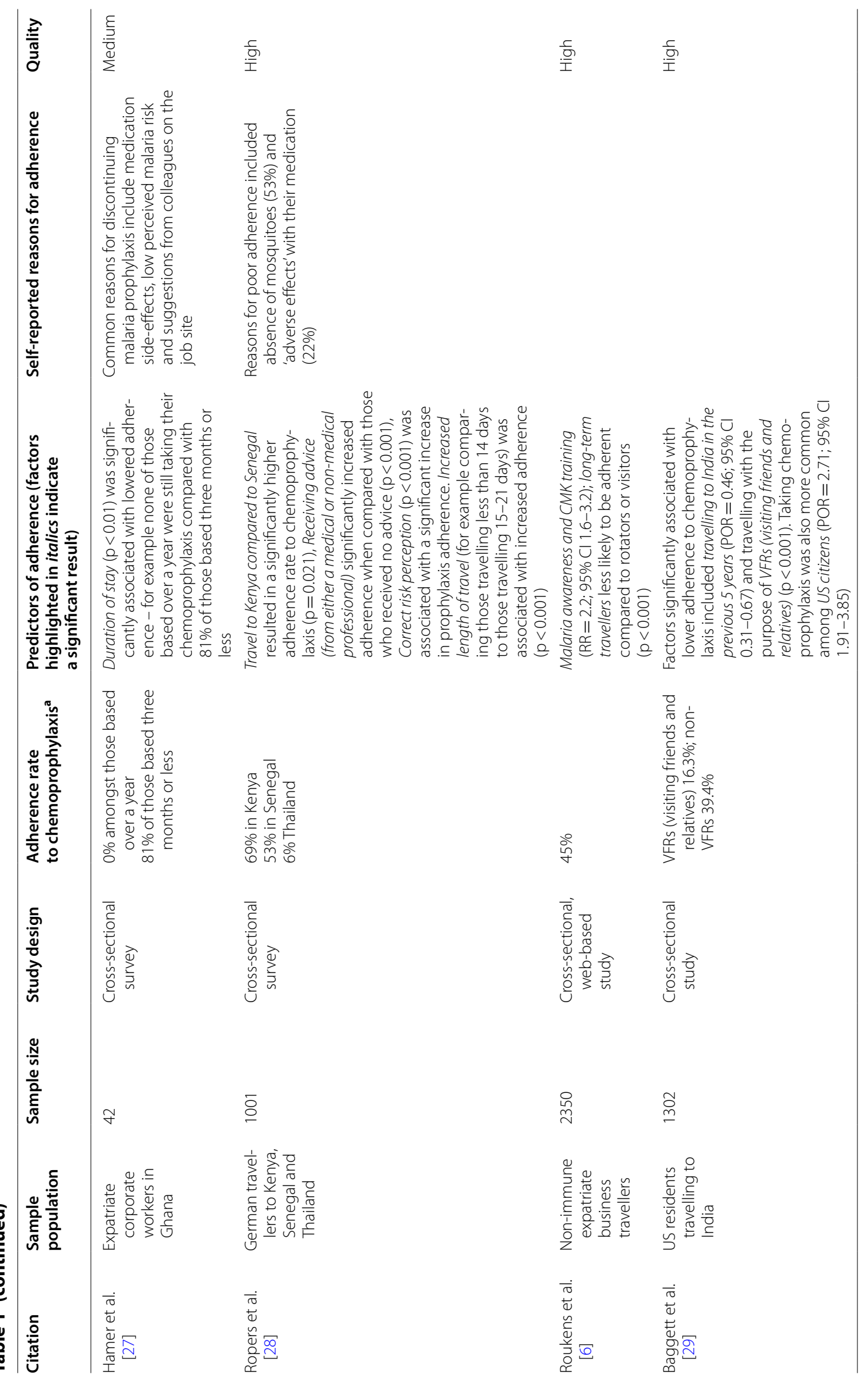




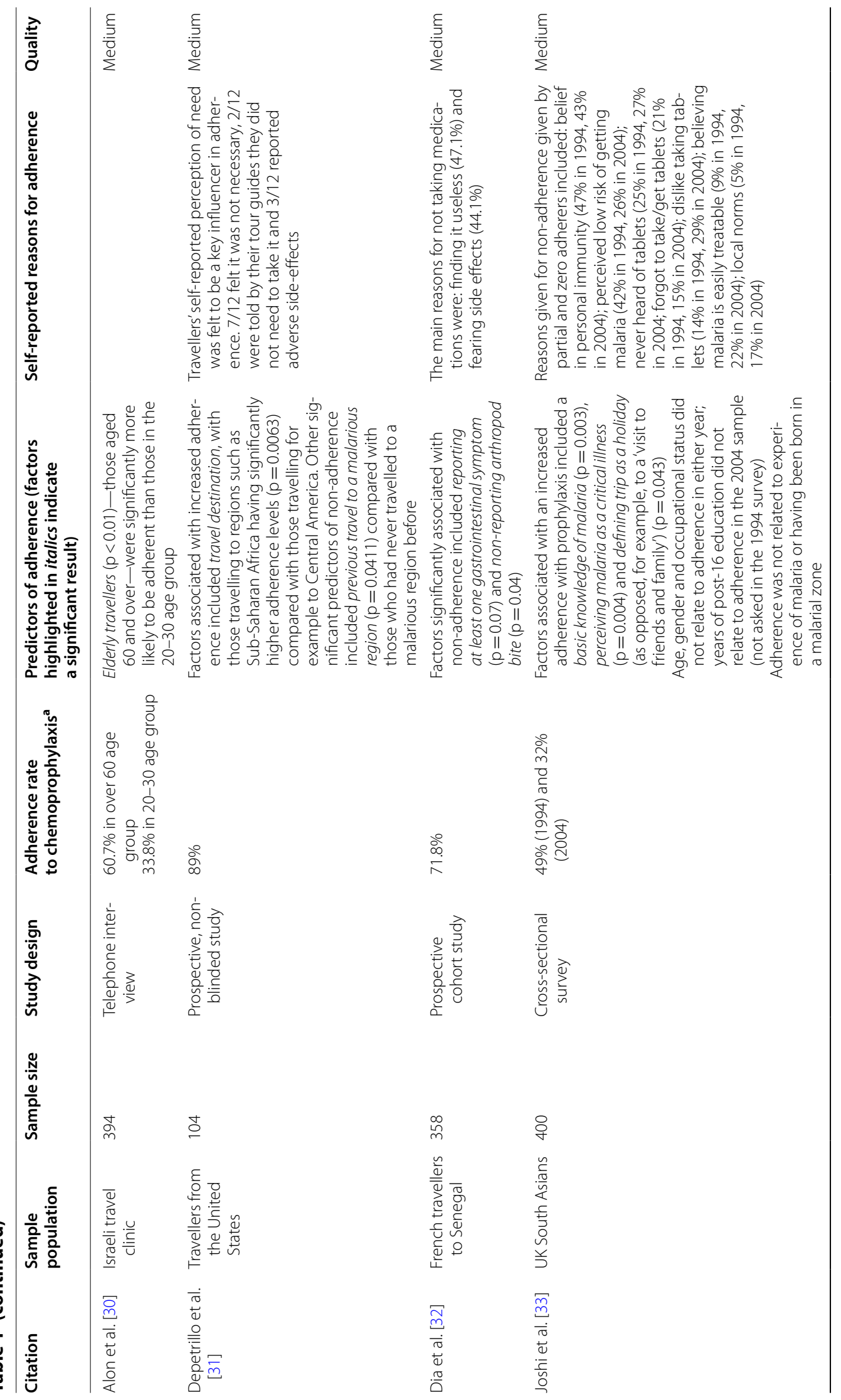




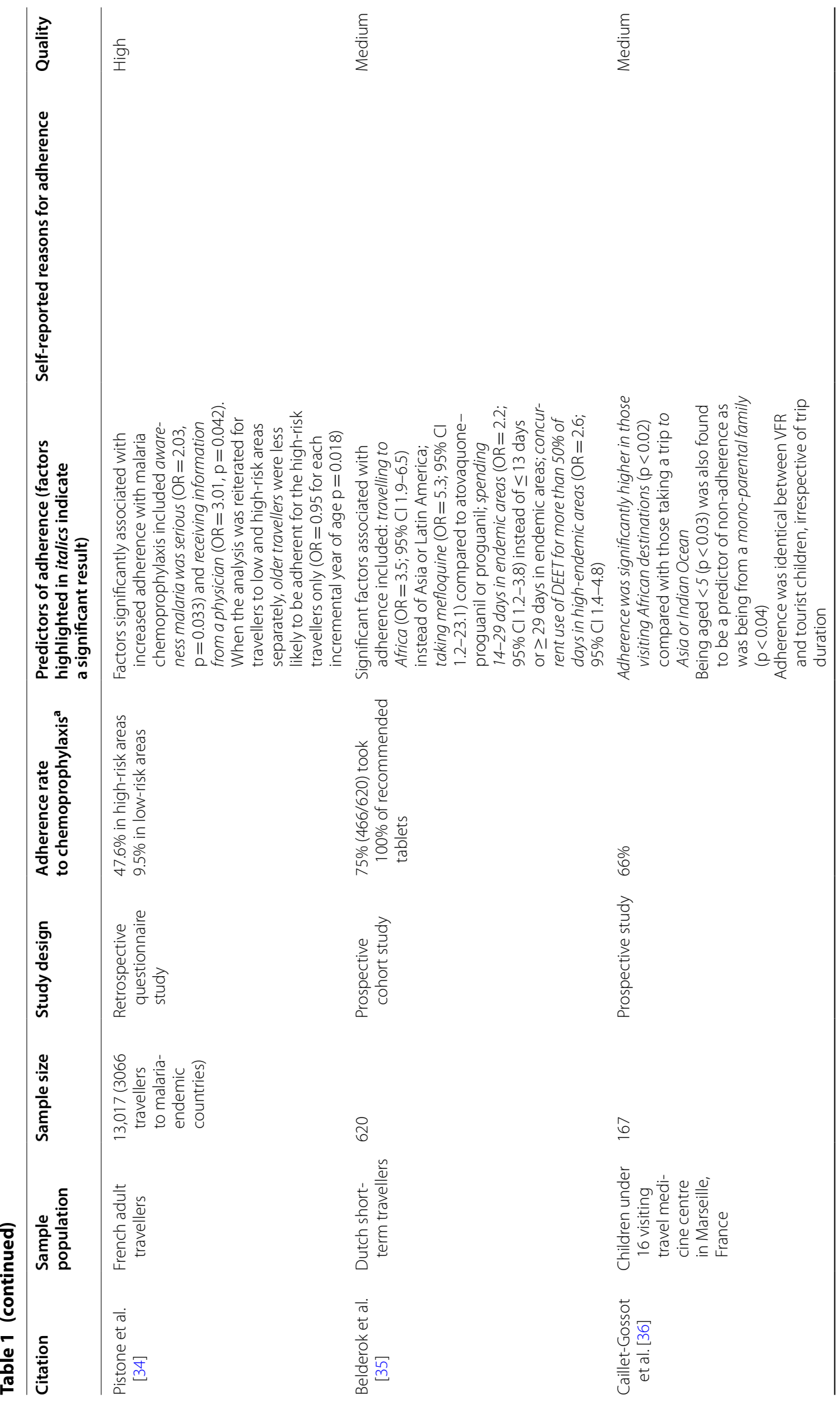




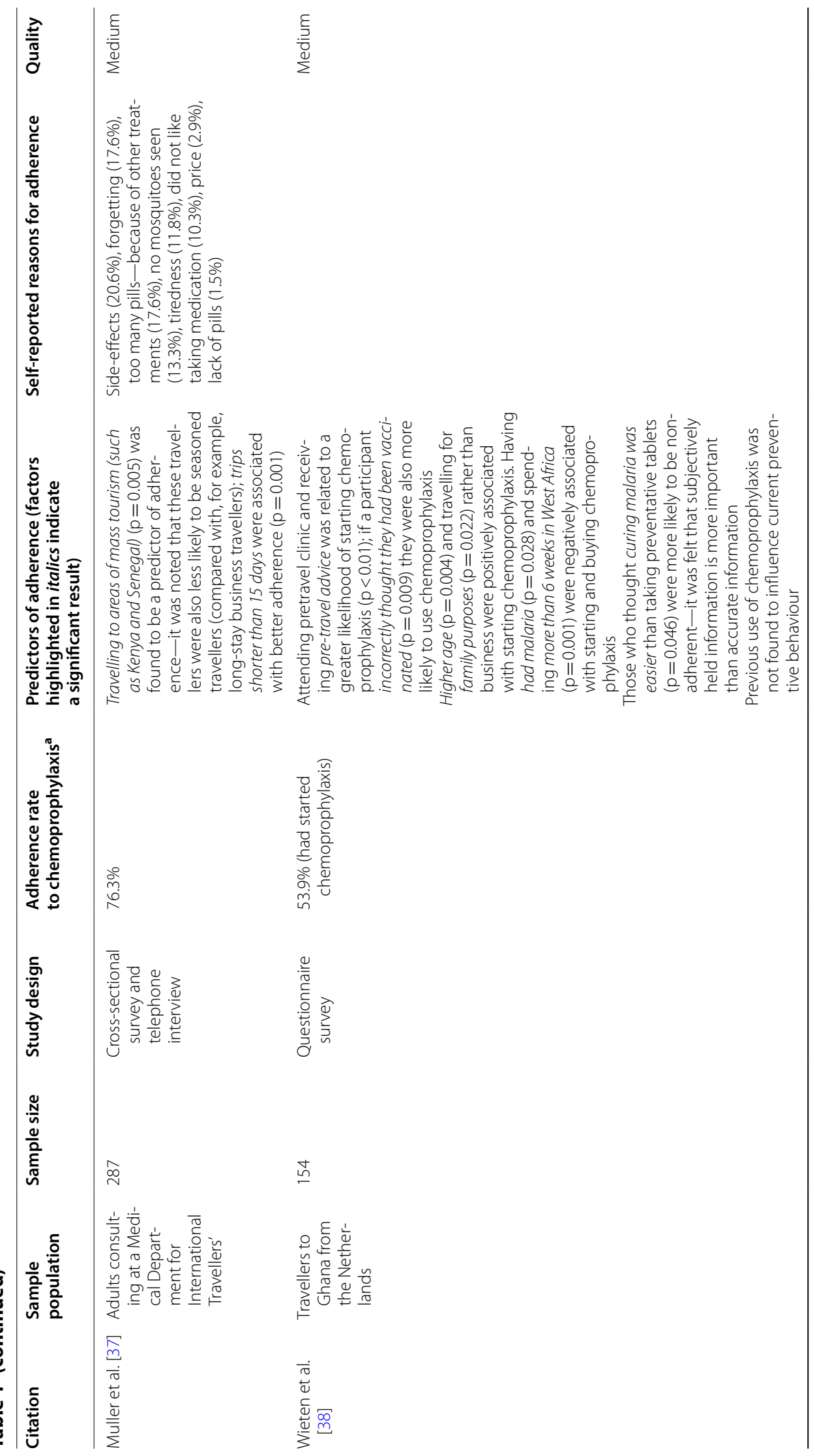




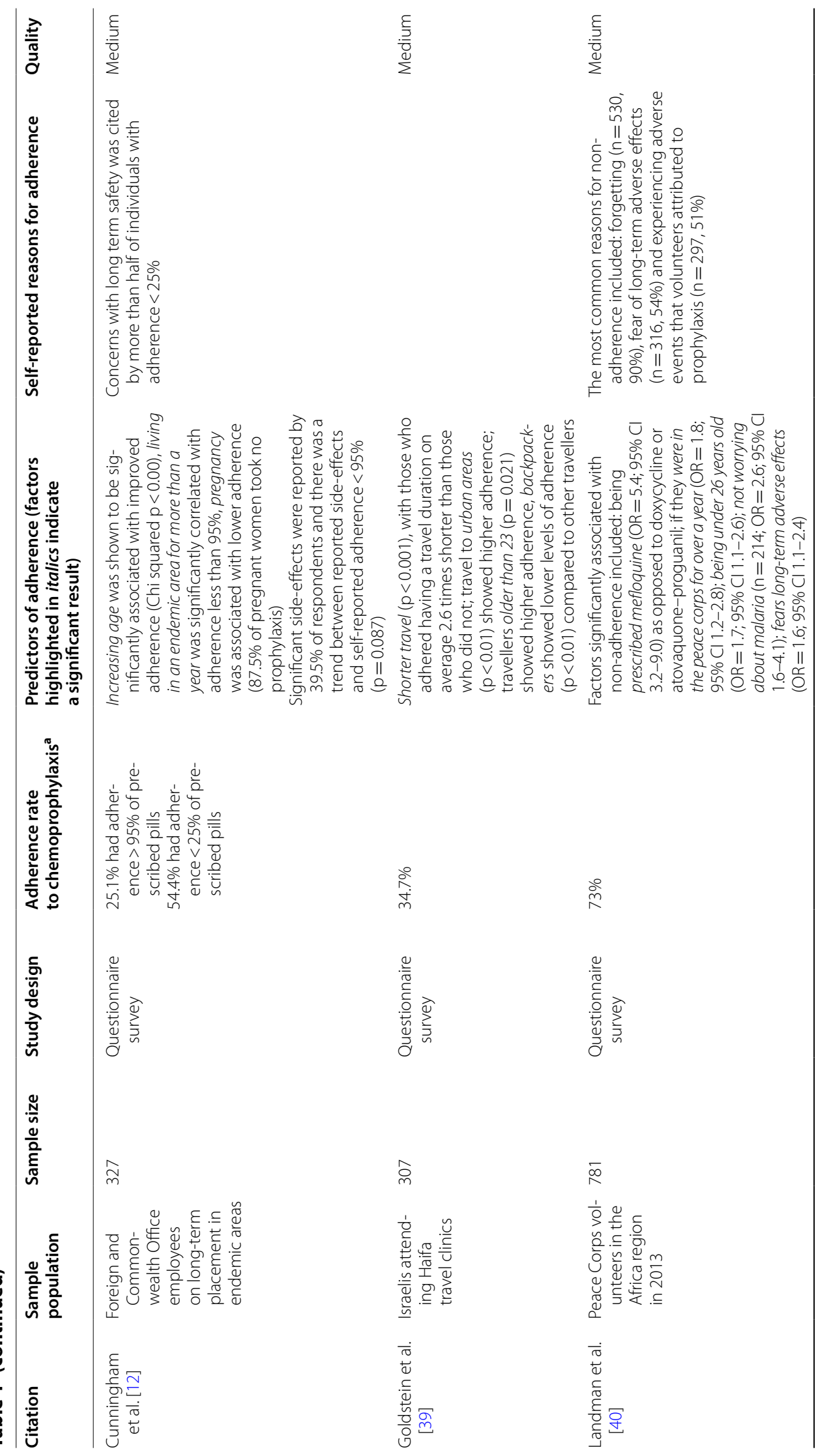




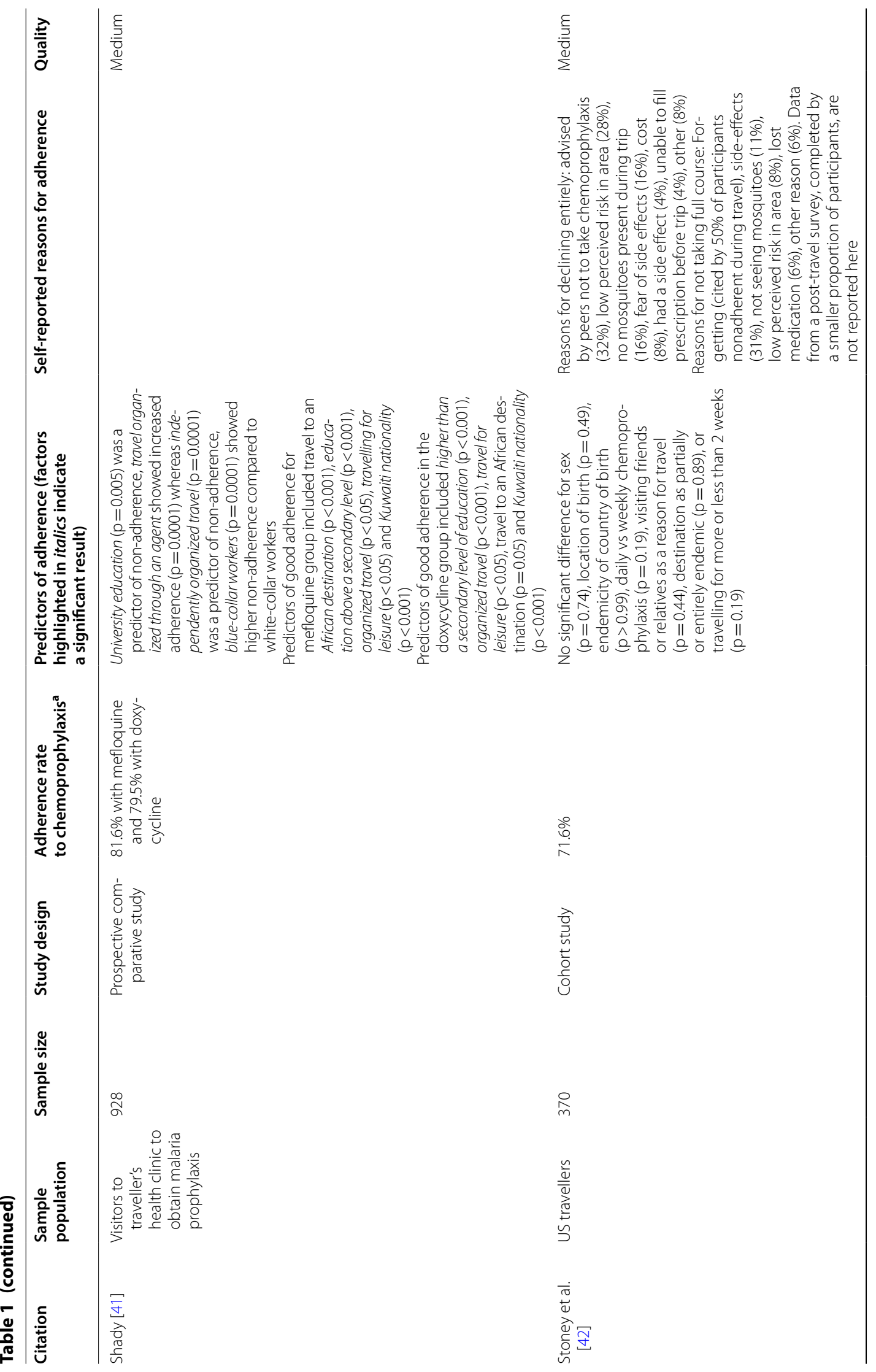




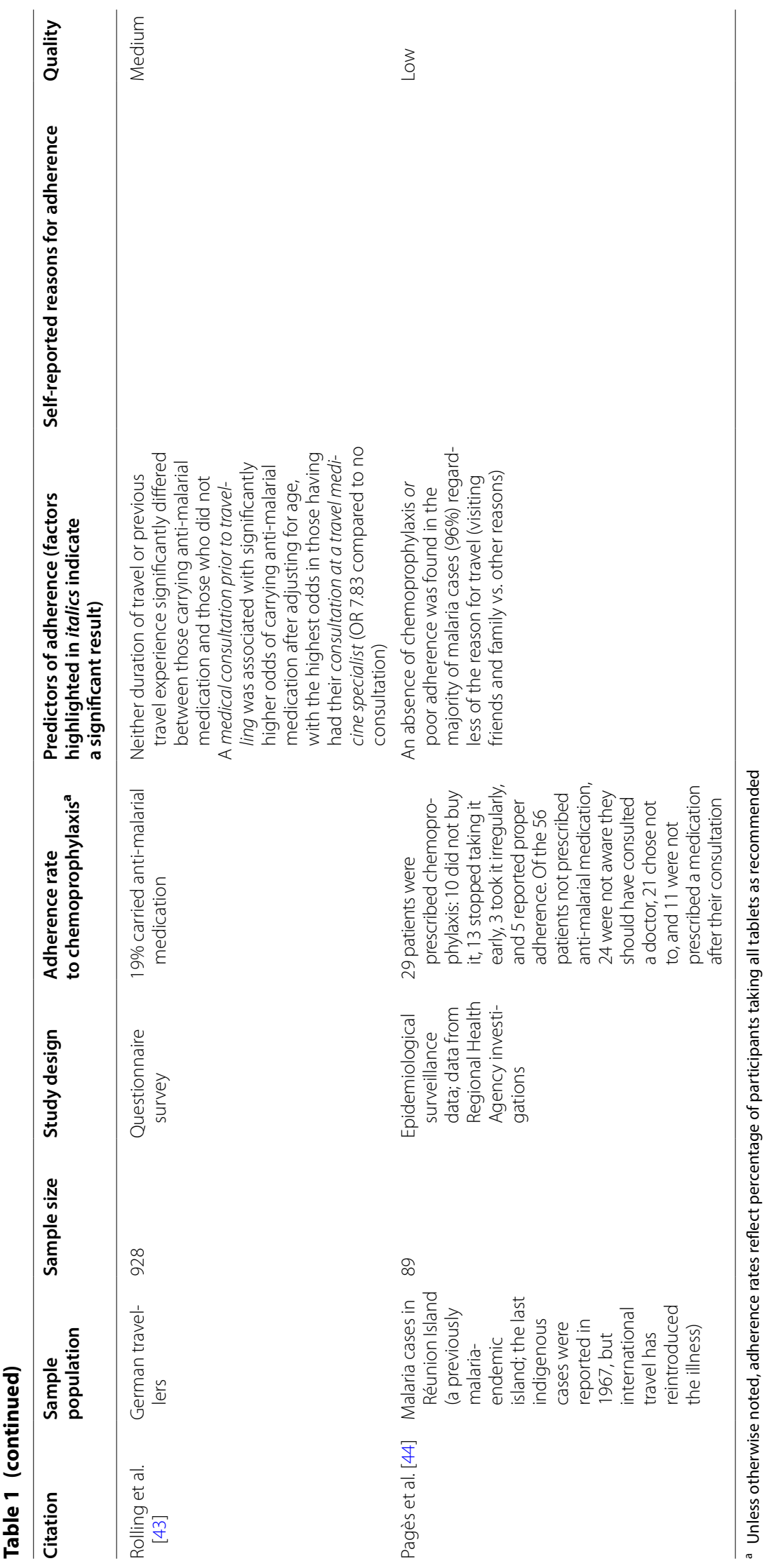


to be non-adherent compared with white-collar workers [41]. Having an above secondary-level education improved adherence, whilst going to university was associated with poor adherence [41]. However, three studies $[14,21,33]$ found no association between education level and adherence. Children from mono-parental families were more likely to exhibit poor adherence [36]. Cobelens et al. [21] and Farquharson et al. [25] found that gender did not significantly predict adherence; one study [22] reported that females were less likely to be adherent than males, though significance was not reported.

\section{Travel-related risk factors}

Length of stay was reported in numerous studies as influencing adherence, with longer stays associated with poorer adherence $[6,12,18,19,24,27,38,40]$. Similarly, shorter travel was shown by most, though not all studies $[28,42]$, to be associated with better adherence [20, 37, 39]. Farquharson et al. [25] found that poor adherence (compared with partial adherence) was associated with going on a longer trip but also noted that full adherence (compared with partial adherence) was associated with going on a longer trip. Belderok et al. [35] noted that those spending 14 to 29 days in an endemic area were significantly more adherent compared with travellers spending less than 13 days, or more than 29 days, in endemic areas. Conversely, two studies [22, 24] found that poor adherence was associated with travelling for more than 3 weeks, though only one of these studies [24] reported the significance level. One study [43] found that duration of travel was not associated with the likelihood of carrying anti-malarial medication.

Previous travel was shown to be a predictor of poor adherence in four studies [19, 29, 31, 33], though one study found no association between previous travel experience and intention to take anti-malarial medication [43] and a further study [14] also found no significant difference in adherence based on previous travel. Having previously acquired malaria [38] was also shown to be associated with lower rates of adherence, though endemicity of country of birth was not [42].

Destination $[20,21,28,31,35,36,41]$ significantly affected adherence. For example, Depetrillo et al. [31] showed that adherence was greater for those travelling to sub-Saharan Africa compared with central America; Ropers et al. [28] showed there was greater adherence in those travelling to Kenya compared with Senegal; and Shady [41], Belderok et al. [35] and Caillet-Gossot et al. [36] demonstrated that adherence was greatest amongst those travelling to African destinations than to Asia, the Indian Ocean or South America. Travel to urban areas [39] or areas of mass tourism [37] was also associated with better adherence rates that those travelling, for example, to rural areas. No effect was found for whether the destination was partially or entirely endemic [42].

The nature and purpose of travel also significantly affected adherence rates. Package tours [20] and those booked through agents [41] compared with more adventurous (e.g. backpacking [21, 39]) or independent [41] travel styles showed greater adherence rates.

Those travelling to visit friends and relatives, for nontourism reasons, or those travelling for business, showed worse adherence in most [18, 24, 29, 33], but not all [44, 42] studies-travelling for family-related as opposed to business-related reasons was shown in one study [38] to be associated with greater adherence. Those travelling for a holiday [33] or leisure [41] showed greater adherence than those travelling for business.

\section{Capability-related risk factors}

Having a basic knowledge of malaria [33] or receiving training [6] was associated with better adherence rates, as was receiving pretravel advice [18, 28, 38]. Farquharson et al. [25] noted that poor adherence (compared to full adherence) was associated with greater amounts of health professional discussion in the medical consultation; they also noted that greater amounts of traveller information and questions were associated with both poor adherence (compared with partial adherence) as well as full adherence (compared with partial adherence). There were variations noted depending on the source of the information, however, with higher adherence rates being reported if information was delivered by a physician, compared with if it was not [34]. Those receiving information from one information source were also more likely to be adherent when compared with those using no information source [18]. Rolling et al. [43] found that travellers were more likely to be carrying anti-malarial medication if they had had a medical consultation prior to travelling, especially with a travel medicine specialist. Forgetting to take tablets, which was a self-reported reason for non-adherence, may also be related to capability $[15,33,37,40,42]$.

\section{Opportunity-related risk factors}

Physical opportunity factors included losing medication or simply not having adequate chemoprophylaxis medication [21, 22]. Social opportunity factors included personal interactions with someone perceived to be knowledgeable about malaria or the side-effects of prophylaxis. Those who received advice from others to discontinue their prophylaxis were less likely to be adherent $[15,21,27,31]$. Being unable to obtain tablets, which was previously explained as a self-reported reason for non-adherence [23, 42], is also related to opportunity. 


\section{Motivation-related risk factors}

Several studies assessed factors relating to motivation. Perhaps the most commonly identified factor was the presence of, or concerns about, side-effects of chemoprophylaxis $[18,19,24,32]$ or concerns about long-term adverse effects of taking the medication [40].

Other motivation related factors included the perceived risk of catching malaria $[28,40]$, the perceived severity of malaria [33, 34], perceived benefits of prophylaxis [14], perceptions and attitudes towards prophylaxis risks and whether the necessity of taking prophylaxis outweighed these risks (notably the safety and side-effects of any medication taken); or wrongly believing [38] that curing malaria would be easier that taking the prophylaxis. Other incorrect beliefs included perceived immunity ([33] - associated with worse adherence) and false belief in being vaccinated ([38] - associated with better adherence), as well as believing that anti-malarial medications are useless [32]. More automatic motivational factors included habitual behaviours such as previous adherence with prophylaxis recommendations and emotional fear of prophylaxis and side-effects. Farquharson et al. [25] found no significant difference in adherence based on previous experience of anti-malarial medication [14].

Low perceived risk, which was often a self-reported reason for non-adherence-as opposed to greater perceived risk, which was related to greater adherence-is also a motivation-related risk factor [23, 26, 27, 33, 42].

\section{Medication-related risk factors}

Several other predictors were identified pertaining to the medication itself. Weekly medication [19] was shown to be more likely to be taken correctly than daily [24] prophylaxis, though not in all studies [42]. Mefloquine showed better adherence rates as opposed to doxycycline or atovaquone-proguanil [40] and better adherence rates compared with atovaquone-proguanil or proguanil [35]. Lobel et al. [24] found that proguanil was associated with poorer adherence. Concurrent use of DEET [35] was also shown to be associated with better adherence.

Two studies $[15,17]$ commented that the majority of poor adherence was due to premature cessation of prophylaxis, when the participants returned home to their non-endemic country.

\section{Discussion}

Despite malaria being largely preventable amongst people travelling from non-endemic countries to endemic ones, it is evident that adherence with the recommended full-course of prophylaxis is poor and many studies reveal 'a largely inadequate use of malaria chemoprophylaxis' [34]. The identified adherence rates among studies identified in this review ranged from $0 \%$ for corporate workers placed in Ghana for over a year [27] to $89 \%$ for travellers from the USA [31]. Thirteen out of the 32 included papers had adherence rates below 50\%. Even amongst those studies which did report higher rates of adherence in certain sub-groups, it was often still possible to identify other sub-groups with poor adherence: for example, although Alon and colleagues reported an adherence rate of $60.7 \%$ in their sample of over 60 -year-olds, this figure was in stark contrast to the rate of $33.8 \%$ reported for their 20-30-year-old sample [30].

Many factors appear to predict adherence. Several of these were repeatedly identified in the literature as important. Destination of travel is one such factor, with travellers to areas in Africa (notably Kenya-[45]) being more likely to adhere to their medication than those traveling to Asia or the Indian Ocean. It is possible that this is due, in part, to travellers perceiving a higher risk in travelling to these countries. Travellers were also more likely to be adherent if visiting urban areas or areas of mass tourism [37], as opposed to rural areas. It is likely that travellers to urban areas and mass tourism areas are also more likely to be inexperienced or travelling for leisure rather than adventure travellers, such as backpackers, and hence hold different attitudes towards prophylaxis.

Age of traveller was shown by many studies to influence adherence rates with older travellers in general having greater adherence rates. The definition of 'old' and 'young' varied significantly between the studies, however, and more research is needed to understand the factors underlying this.

Similarly, length of travel [27] was identified as a key influencer of adherence, with travellers' adherence falling the longer they were away. This was of note amongst expatriates and peace corps volunteers. Multiple factors might contribute to this effect, including false beliefs in immunity, side-effects, and fears of adverse effects from long-term medication use. Certainly, experiencing or expecting to experience side-effects [32], was a common factor influencing adherence. In this particular study, 'individuals who reported at least one gastrointestinal symptom (assigned or not to anti-malarials) were more likely to be noncompliant'.

Encouragingly, education [41], awareness training (e.g. covering 'the correct use of the curative medication and the need to seek medical care' [6]) and pretravel advice was shown to increase adherence with prophylaxis as was consistent information from more than one source. A key role of information may be generating accurate risk perceptions. For those offering advice to travellers, efforts should be made to identify the travellers' level of understanding of malaria, the likelihood of contracting it and its severity, and attempt to tailor advice accordingly. 
Travellers may incorrectly assume that curing malaria is easier than having to take the prophylaxis.

Another key finding of the review was that the reason for travel was a strong predictor of adherence rates. Business travellers [18] were significantly more likely to have low adherence compared to those travelling for leisure. Backpackers/adventure travellers [39] had lower adherence in comparison with those on package tours. Those reporting that they were visiting friends and relatives [33] were also significantly less likely to follow chemoprophylaxis recommendations. Many reasons were put forward for these trends. For example, backpackers may be less likely to follow recommendations because they are less informed about the risks having not received advice from a travel agent, because they have not contracted malaria before and perceive their risk to be low, or because they are younger and less concerned with health risks in general.

The results of this review have implications for clinicians who may be able to improve adherence rates of malaria prophylaxis. Many previous attempts at adherence interventions have been unsuccessful, perhaps due to being developed without a sound theoretical basis, lacking a tailored approach matching interventions and individual determinants of non-adherence, and focusing solely on provision of information $[9,46]$. Research has therefore moved on to models focusing on patients' beliefs, abilities and motivations [9]. One example of this is the Capability, Opportunity and Motivation (COMB) model of behaviour [10], suggesting that behaviour is influenced by the interaction between capability, opportunity and motivation-and, importantly, that behaviour could be modified by targeting these three factors. Allemann et al. [46] developed a list of modifiable determinants of adherence (such as knowledge, beliefs about capabilities, beliefs about consequences, intentions, and memory, among others) and suggested that such determinants should be assessed and matched to appropriate interventions. It is important that future interventions aimed at improving adherence should be personalized, targeting the causes of non-adherence per individual, and should apply the COM-B model rather than simply providing information to patients.

\section{Quality of the literature}

The quality of this systematic review was limited by the methods of the studies reviewed. In this regard, it is notable that only eight included studies were rated as being high quality. Many of the studies used different methods to assess adherence, and factors influencing adherence, amongst a wide range of participants. The definitions of adherence and the length of recommended treatment also differ greatly from study to study, meaning that a participant defined as adherent in one study might not have been in another. For example, Cunningham et al. [12] defined adherence as taking more than $95 \%$ of prescribed tablets, whereas Belderok et al. [35] reported those who took all their prescribed tablets; Rolling et al. [43] explored intention to adhere to anti-malarial medication simply by asking travellers at an airport if they were carrying tablets. The reliance of many studies on self-reported measures of adherence was also notable. Self-report has limitations as a method, reflecting participant recall and social desirability as well as genuine adherence. Future studies should explore alternative ways of measuring adherence.

The eight high-quality studies tended to have larger participant samples (ranging from 1001 to 42,202). It is perhaps an issue that many studies in this area use small sample sizes and there is a lack of large-scale randomized controlled trials. Those who reported overall adherence rates of the whole sample reported fairly similar prevalence rates (42.4-61.7\%). Four of the eight high-quality studies examined pre-travel knowledge/advice as a determinant of adherence, and all found it a significant predictor, while three explored reason for travel and found that non-tourism reasons for travelling were associated with lower adherence.

\section{Quality of this review}

Positively, the findings of this review seem to broadly correspond with a previous review, published in the form of a poster presentation and letter [14, 47]. However, there are some limitations to the review process. Due to pragmatic considerations, this review was limited to papers published in English. Papers in other languages, or which appeared only in the grey literature, may exist which would have added to the conclusions. Similarly, because the initial search itself was carried out by one individual, human error in the compilation of the literature database cannot be discounted. This may have resulted in some studies being erroneously excluded. Because studies with significant findings are more likely to be published and are usually easier to locate and identify, it is possible that some of the apparent predictors of adherence that were identified may be less robust than it currently appears. It should also be noted that conclusions are inevitably constrained by what currently exists in the literature and there may be scope for other, more imaginative interventions to promote adherence. It is also possible that there are different reasons for non-adherence in different populations and that reviews not focusing solely on travellers from non-endemic countries may uncover other factors associated with non-adherence. 


\section{Conclusions}

This review identified several predictors of actual and intended adherence to malaria prophylaxis, ranging from country visited, the length of time travelling, and the purpose of visit, amongst other things. Whilst further research in this area is needed, it is hoped that some of these findings may be taken forward to inform interventions. The results suggest that to improve adherence clinicians should concentrate their attention on those groups identified as least likely to exhibit adherent behaviour. They should ensure that they focus on travellers visiting destinations known to have lower adherence rates (such as rural areas), backpackers, business travellers, younger travellers and those travelling for longer periods of time. They should check to ensure that a traveller's perceived risk of catching malaria is equivalent to the actual risks of travelling and that they do not, for example, wrongly believe that curing malaria is easier than taking prophylaxis or falsely believe that they have some level of innate immunity because they are visiting relatives. All travellers should be informed of the potential side-effects of medication and given guidance on why it is nonetheless beneficial to continue to take prophylaxis medication.

\section{Abbreviations}

PRISMA: preferred reporting items for systematic reviews and meta-analyses.

\section{Acknowledgements}

Not applicable.

\section{Authors' contributions \\ All authors conceived the review. JA conducted the initial search and data extraction. GJR conducted the 2017 update. SKB conducted the 2019 update. JA wrote the first draft of the manuscript. All authors contributed to further drafts. All authors read and approved the final manuscript.}

\section{Funding}

The research was funded by the National Institute for Health Research Health Protection Research Unit (NIHR HPRU) in Emergency Preparedness and Response at King's College London in partnership with Public Health England (PHE), in collaboration with the University of East Anglia and Newcastle University. The views expressed are those of the author(s) and not necessarily those of the NHS, the NIHR, the Department of Health or Public Health England.

The funding body had no role in the design of the study, nor in the collection, analysis and interpretation of data, nor in writing the manuscript.

\section{Availability of data and materials}

Not applicable.

\section{Ethics approval and consent to participate}

Not applicable.

\section{Consent for publication}

Not applicable.

\section{Competing interests}

The authors declare that they have no competing interests.

\section{Author details}

1 King's College London, GKT School of Medical Education, London, UK.

${ }^{2}$ Department of Psychological Medicine, King's College London, Weston
Education Centre, Cutcombe Road, London SE5 9RJ, UK. ${ }^{3}$ King's College London, Institute of Pharmaceutical Science, London, UK.

Received: 8 October 2019 Accepted: 7 January 2020

Published online: 13 January 2020

\section{References}

1. 10 facts on malaria. http://www.who.int/features/factfiles/malaria/en.

2. Morgan M, Figueroa-Munoz JI. Barriers to uptake and adherence with malaria prophylaxis by the African community in London, England: focus group study. Ethn Health. 2005;10:355-72.

3. International travel and health: Malaria. http://www.who.int/ith/2015-ithchapter7.pdf.

4. Croft AM, Jacquerioz FA, Jones KL. Drugs to prevent malaria in travellers: a systematic review of randomized controlled trials. Hum Parasit Dis. 2010;2:1-19.

5. Malaria in the UK: annual report https://www.gov.uk/government/publi cations/malaria-in-the-uk-annual-report.

6. Roukens AH, Berg J, Barbey A, Visser LG. Performance of self-diagnosis and standby treatment of malaria in international oilfield service employees in the field. Malar J. 2008;7:128.

7. Malaria prophylaxis https://cks.nice.org.uk/malaria-prophylaxis.

8. Public Health England. Guidelines for malaria prevention in travellers from the UK 2019 https://assets.publishing.service.gov.uk/government /uploads/system/uploads/attachment_data/file/833506/ACMP_Guide lines.pdf.

9. Jackson C, Eliasson L, Barber N, Weinman J. Applying COM-B to medication adherence: a suggested framework for research and interventions. Eur J Health Psychol. 2014;16:7-17.

10. Michie S, van Stralen MM, West R. The behaviour change wheel: a new method for characterising and designing behaviour change interventions. Implement Sci. 2011;6:42.

11. Moher D, Liberati A, Tetzlaff J, Altman DG, Prisma Group. Preferred reporting items for systematic reviews and meta-analyses: the PRISMA statement. PLoS Med. 2009;6:e1000097.

12. Cunningham J, Horsley J, Patel D, Tunbridge A, Lalloo DG. Compliance with long-term malaria prophylaxis in British expatriates. Travel Med Infect Dis. 2014;12:341-8.

13. Verhagen AP, de Vet HC, de Bie RA, Kessels AG, Boers M, Bouter LM, et al. The Delphi list: a criteria list for quality assessment of randomized clinical trials for conducting systematic reviews developed by Delphi consensus. J Clin Epidemiol. 1998:51:1235-41.

14. Bocci G, Troiano G, Golinelli D, Verzuri A, Rossi S, Nante N. Compliance with malaria chemoprophylaxis in travelers: a systematic review. Eur J Public Health. 2016;26(suppl_1):ckw174.229.

15. Phillips-Howard PA, Blaze M, Hurn M, Bradley DJ. Malaria prophylaxis: survey of the response of British travellers to prophylactic advice. BMJ (Clin Res Ed). 1986;293:932-4

16. Lobel MD, Campbell CC, Pappaioanu M, Huong AY. Use of prophylaxis for malaria by American travelers to Africa and Haiti. JAMA. 1987;257(19):2626-27.

17. Hilton E, Edwards B, Singer C. Reported illness and compliance in us travelers attending an immunization facility. Arch Int Med. 1989;149:178-9.

18. Lobel HO, Phillips-Howard PA, Brandling-Bennett AD, Steffen R, Campbell $C C$, Huong AY, et al. Malaria incidence and prevention among European and North American travellers to Kenya. Bull World Health Organ. 1990;68:209-15.

19. Steffen R, Heusser R, Machler R, Bruppacher R, Naef U, Chen D, et al. Malaria chemoprophylaxis among European tourists in tropical Africa: use, adverse reactions, and efficacy. Bull World Health Organ. 1990;68:313-22.

20. Held TK, Weinke T, Mansmann U, Trautmann M, Pohle HD. Malaria prophylaxis: identifying risk groups for non-compliance. Q J Med. 1994;87:17-22.

21. Cobelens FG, Leentvaar-Kuijpers A. Compliance with malaria chemoprophylaxis and preventative measures against mosquito bites among Dutch travellers. Trop Med Int Health. 1997;2:705-13.

22. Chatterjee S. Compliance of malaria chemoprophylaxis among travelers to India. J Travel Med. 1999;6:7-11. 
23. Banerjee D, Stanley PJ. Malaria chemoprophylaxis in UK general practitioners traveling to South Asia. J Travel Med. 2001;8:173-5.

24. Lobel HO, Baker MA, Gras FA, Stennies GM, Meerburg P, Hiemstra E, et al Use of malaria prevention measures by North American and European travelers to East Africa. J Travel Med. 2001;8:167-72.

25. Farquharson L, Noble LM, Barker C, Behrens RH. Health beliefs and communication in the travel clinic consultation as predictors of adherence to malaria chemoprophylaxis. Br J Health Psychol. 2004;9:201-17.

26. Jute S, Toovey S. Knowledge, attitudes and practices of expatriates towards malaria chemoprophylaxis and personal protection measures on a mine in Mali. Travel Med Infect Dis. 2007;5:40-3.

27. Hamer DH, Ruffing R, Callahan MV, Lyons SH, Abdullah ASM. Knowledge and use of measures to reduce health risks by corporate expatriate employees in Western Ghana. J Travel Med. 2008;15:237-42.

28. Ropers G, Du Ry van Beest Holle M, Wichmann O, Kappelmayer L, Stüben $U$, Schönfeld C, et al. Determinants of malaria prophylaxis among german travelers to Kenya, Senegal, and Thailand. J Travel Med. 2008;15:162-71.

29. Baggett HC, Graham S, Kozarsky PE, Gallagher N, Blumensaadt S, Bateman J, et al. Pretravel health preparation among US residents traveling to India to VFRs: importance of ethnicity in defining VFRs. J Travel Med. 2009;16:112-8.

30. Alon D, Shitrit P, Chowers M. Risk behaviors and spectrum of diseases among elderly travelers: a comparison of younger and older adults. J Travel Med. 2010;17:250-5.

31. DePetrillo JC, Singer C, Bergagnini IA, Kolakowski P, Edwards B, Smith MA. Assessment of adherence to atovaquone-proguanil prophylaxis in travelers. J Travel Med. 2010;17:217-20.

32. Dia A, Gautret $P$, Adheossi E, Bienaimé A, Gaillard C, Simon F, et al. Illness in French travelers to Senegal: prospective cohort follow-up and sentinel surveillance data. J Travel Med. 2010;17:296-302.

33. Joshi MS, Lalvani A. 'Home from home': risk perceptions, malaria and the use of chemoprophylaxis among UK South Asians. Ethn Health. 2010;15:365-75.

34. Pistone T, Ezzedine K, Gaudin A-F, Hercberg S, Nachbaur G, Malvy D. Malaria prevention behaviour and risk awareness in French adult travellers. Travel Med Infect Dis. 2010;8:13-21.

35. Belderok S-M, van den Hoek A, Roeffen W, Sauerwein R, Sonder GJB. Adherence to chemoprophylaxis and Plasmodium falciparum anticircumsporozoite seroconversion in a prospective cohort study of Dutch short-term travelers. PLoS ONE. 2013;8:e56863.
36. Caillet-Gossot S, Laporte R, Noël G, Gautret P, Soula G, Delmont J, et al. Family compliance with counseling for children traveling to the Tropics. J Travel Med. 2013:20:171-6.

37. Muller JM, Simonet AL, Binois R, Muggeo E, Bugnon P, Liet J, et al. The respect of recommendations provided in an international travelers' medical service: far from the cup to the lips. J Travel Med. 2013;20:78-82.

38. Wieten RW, Harting J, Biemond PM, Grobusch MP, van Vugt M. Towards improved uptake of malaria chemoprophylaxis among West African travellers: identification of behavioural determinants. Malar J. 2013;12:360.

39. Goldstein I, Grefat R, Ephros M, Rishpon S. Intent-to-adhere and adherence to malaria prevention recommendations in two travel clinics. $J$ Travel Med. 2014;22:130-2.

40. Landman KZ, Tan KR, Arguin PM. Adherence to malaria prophylaxis among Peace Corps Volunteers in the Africa region, 2013. Travel Med Infect Dis. 2015;13:61-8.

41. Shady I. Determinants of adherence with malaria chemoprophylactic drugs used in a traveler's health clinic. J Travel Med. 2015;2015:163716.

42. Stoney RJ, Chen LH, Jentes ES, Wilson ME, Han PV, Benoit CM, et al. Malaria prevention strategies: adherence among Boston area travelers visiting malaria-endemic countries. Am J Trop Med Hyg. 2016;94:136-42.

43. Rolling T, Mühlenpfordt M, Addo MM, Cramer JP, Vinnemeier CD. Pretravel advice at a crossroad: medical preparedness of travellers to South and Southeast-Asia — the Hamburg airport survey. Travel Med Infect Dis. 2017:18:41-5.

44. Pagès F, Houze S, Kurtkowiak B, Balleydier E, Chieze F, Filleul L. Status of imported malaria on Réunion Island in 2016. Malar J. 2018;17:210.

45. Behrens RH, Alexander N. Malaria knowledge and utilization of chemoprophylaxis in the UK population and in UK passengers departing to malaria-endemic areas. Malar J. 2013;12:461.

46. Allemann SS, Nieuwlaat R, van den Bemt BJF, Hersberger KE, Arnet I. Matching adherence interventions to patient determinants using the theoretical domains framework. Front Pharmacol. 2016;7:429.

47. Bocci G, Troiano G, Golinelli D, Verzuri A, Rossi S, Nante N. Malaria chemoprophylaxis' compliance in travelers. Ann Ig. 2018;30:71-2.

\section{Publisher's Note}

Springer Nature remains neutral with regard to jurisdictional claims in published maps and institutional affiliations.
Ready to submit your research? Choose BMC and benefit from:

- fast, convenient online submission

- thorough peer review by experienced researchers in your field

- rapid publication on acceptance

- support for research data, including large and complex data types

- gold Open Access which fosters wider collaboration and increased citations

- maximum visibility for your research: over $100 \mathrm{M}$ website views per year

At BMC, research is always in progress.

Learn more biomedcentral.com/submissions 